\title{
Inflammatory Myofibroblastic Tumor of Bladder
}

\author{
${ }^{1}$ Rohit Juneja, ${ }^{2} \mathrm{HS}$ Veerendra
}

\begin{abstract}
Inflammatory myofibroblastic tumor (IMT) is a rare benign lesion found in many locations throughout the body and genitourinary tract. In bladder, being very uncommon, it arises from submucosal stroma as a polypoidal growth, and is easily mistaken for a malignant neoplasm-both clinically and radiologically. Essential criteria for the diagnosis of IMT are spindle myoepithelial cell proliferation and lymphoplasmacytic infiltrate. Here, we report a case of a 29-year-old male who presented with painless gross hematuria for 3 days. The patient underwent transurethral resection of the tumor and the final pathological diagnosis was IMT of the bladder.
\end{abstract}

Keywords: Immunohistochemical staining, Inflammatory myofibroblastic tumor, Spindle myoepithelial cell proliferation.

How to cite this article: Juneja R, Veerendra HS. Inflammatory Myofibroblastic Tumor of Bladder. Int J Recent Surg Med Sci 2017;3(2):109-110.

\section{Source of support: Nil}

Conflict of interest: None

\section{INTRODUCTION}

Inflammatory myofibroblastic tumor (IMT) is a rare tumor with a malignant potential, and is also known as inflammatory pseudotumor. It has been described in many organs including lungs ${ }^{1}$ being the most common, liver, ${ }^{2}$ and skin. ${ }^{3}$ In genitourinary tract (GUT) system, it likely starts in the bladder, but has also been reported in kidney, ureter, ${ }^{4}$ prostate, and epididymis. ${ }^{5}$

The first case of bladder IMT was reported by Roth in $1980 .{ }^{6}$ A study including 42 cases of IMT of the bladder was reported by American pathologists in 2006. ${ }^{7}$ A high index of suspicion is required for the diagnosis of IMT, as it is often difficult to distinguish from its malignant counterpart, and being locally aggressive, close followup is warranted. Here, we report a new case of IMT of urinary bladder and discuss its clinical presentation, diagnosis, and management.

${ }^{1}$ Resident, ${ }^{2}$ Associate Professor

1,2Department of Urology, S. S. Institute of Medical Sciences and Research Centre, Davangere, Karnataka, India

Corresponding Author: Rohit Juneja, Resident, Department of Urology, S. S. Institute of Medical Sciences and Research Centre, Davangere, Karnataka, India, Phone: +919108927347 e-mail: rj.juneja@gmail.com

\section{CASE REPORT}

A 29-year-old male presented to the urology outpatient department with complaint of gross painless hematuria with passage of clots since previous 3 days $/ 1$ week. The patient complained of burning micturition and denied any history of fever, trauma, recurrent urinary tract infection, bladder instrumentation, calculi, sexually transmitted disease, or weight loss. There was no past history of similar complaints or tuberculosis. Initial ultrasound (Fig. 1) showed dependent mobile echogenic lesion on posterior wall of bladder measuring $42 \times 30 \mathrm{~mm}$ in size and was likely to be cystitis with organized hematoma. However, computed tomography of kidneys, ureters, bladder showed irregular heterogeneously enhancing polypoidal lesion in bladder with almost similar size and no obvious suspicious lymph node. Lab studies showed decreased hemoglobin and microscopic hematuria, rest being normal. Cystopan-endoscopy revealed papillary growth of size approximately $3 \times 2 \mathrm{~cm}$ on posterolateral wall of bladder with organized clot over it. Complete transurethral resection with deep biopsies was taken from the site. Microscopically, the report dictated normally appearing urothelium with edematous stroma and proliferating spindle cells. Cells showed mild degree of pleomorphism, elongated vesicular prominent nucleoli, and tapered cytoplasm with occasional mitosis. Stroma showed mixed inflammation including occasional eosinophil, extravasated red blood cells, and thin-walled blood vessels. On immunohistochemistry, tumor expressed desmin, smooth muscle actin, and anaplastic lymphoma kinase (ALK)-1, and final pathologic diagnosis was IMT of bladder with no muscle invasion.

\section{DISCUSSION}

The IMT of bladder is an uncommon tumor of controversial nosology; it is at the edge between benign and malignant tumors and is also known as pseudosarcoma, atypical myfibroblastic tumor, atypical fibromyxoid tumor, plasma cell granuloma. ${ }^{8}$ It is idiopathic and no known predisposing condition exists for myofibroblastic tumor of the bladder. ${ }^{9}$ The first case was reported by Roth in $1980 .{ }^{6}$ It can affect any age group, but is more common in children and young adults with slight female preponderance (F:M ratio 3:4). ${ }^{6}$ The most common site for this tumor is lung. ${ }^{10}$ It is rare in the GUT, with the most common site being urinary bladder. A recent 


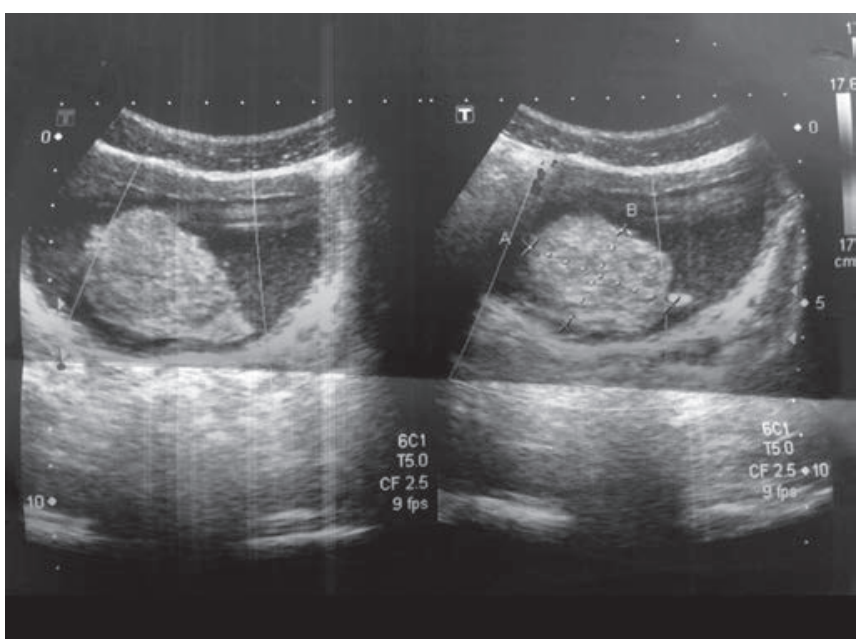

Fig. 1: Ultrasonography film of tumor

report suggests that it is neoplastic because of its aggressive behavior, involvement of chromosome $2 \mathrm{p} 23$, and cytogenetic monoclonality. Also, it has the potential for recurrence and persistent local growth. Essential criteria for the diagnosis of IMT are spindle myoepithelial cell proliferation and lymphocytic infiltrate (Fig. 2). Immunohistochemical staining may demonstrate positivity for ALK, vimentin, cytokeratin. The ALK has been described as a good marker for IMT. ${ }^{11}$ Initial biopsy and full histopathological examination are recommended where complete resection is problematic. Complete surgical resection is performed to avoid local recurrence. Being locally aggressive and difficult to distinguish from its malignant counterpart, a high index of suspicion is required for the diagnosis, and therefore, close followup is warranted.

\section{REFERENCES}

1. Chen CK, Jan CI, Tsai JS, Huang HC, Chen PR, Lin YS, Chen CY, Fang HY. Inflammatory myofibroblastic tumor of the lung: a case report. J Cardiothorac Surg 2010 Jul;5(1):55.

2. Sari A, Tunakan M, Ünsal B, Ekıncı N, Rezanko T, Elçın F, Aydoğdu Z. Inflammatory pseudotumor of the liver diagnosed by needle biopsy: report of three cases (one with neuroendocrine tumor of the rectum and lung). Turk J Gastroenterol 2010 Sep;21(3):308-312.

3. Son SB, Heo YS, Shin WW, Oh TS, Song HJ, Oh CH. A case of cutaneous inflammatory myofibroblastic tumor. Ann Dermatol 2010 Feb;22(1):91-95.

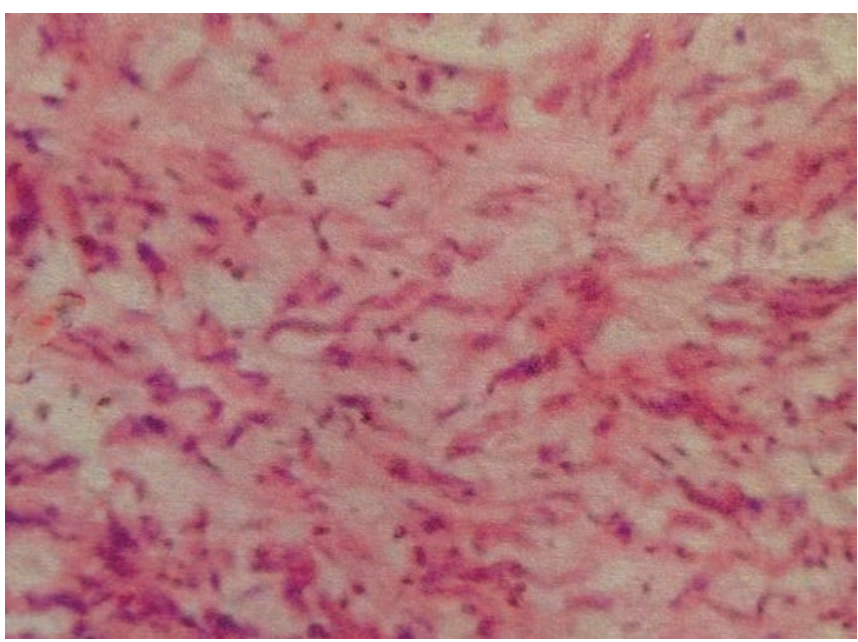

Fig. 2: Immunohistochemistry image

4. Montgomery EA, Shuster DD, Burkart AL, Esteban JM, Sgrignoli A, Elwood L, Vaughn DJ, Griffin CA, Epstein JI. Inflammatory myofibroblastic tumors of the urinary tract: a clinicopathologic study of 46 cases, including a malignant example inflammatory fibrosarcoma and a subset associated with high-grade urothelial carcinoma. Am J Surg Pathol 2006 Dec;30(12):1502-1512.

5. Tunuguntla H, Mishra A, Jorda M, Gosalbez R. Inflammatory myofibroblastic tumor of the epididymis: case report and review of the literature. Urology 2011 Jul;78(1):183-185.

6. Roth JA. Reactive pseudosarcomatous response in urinary bladder. Urology 1980 Dec;16(6):635-637

7. Harik LR, Merino C, Coindre JM, Amin MB, Pedeutour F, Weiss SW. Pseudosarcomatous myofibroblastic proliferations of the bladder: a clinicopathologic study of 42 cases. Am J Surg Pathol 2006 Jul;30(7):787-794.

8. Jones EC, Clement PB, Young RH. Inflammatory pseudotumor of the urinary bladder A clinicopathological, immunohistochemical, ultrastructural, and flow cytometric study of 13 cases. Am J Surg Pathol 1993 Mar;17(3):264-274.

9. Pettinato G, Manivel JC, De Rosa N, Dehner LP. IMT (plasma cell granuloma): Clinicopathologic study of 20 cases with immunohistochemical and ultrastructural observations. Am J Clin Pathol 1990 Nov;94(5):538-546.

10. Coffin CM, Watterson J, Priest JR, Dehner LP. Extrapulmonary inflammatory myofibroblastic tumor (inflammatory pseudotumor): a clinic pathologic and immuno-histochemical study of 84 cases. Am J Surg Pathol 1995 Aug;19(8):859-872.

11. Cessna MH, Zhou H, Perkins SL, Tripp SR, Layfield L, Daines C, Coffin CM. Are myogenin and myoD1 expression specific for rhabdomyosarcoma? A study of 150 cases, with emphasis on spindle cell mimics. Am J Surg Pathol 2001 Sep;25(9):1150-1157. 